Article

\title{
A Printed Wearable Dual-Band Antenna for Wireless Power Transfer
}

\author{
Mohammad Haerinia ${ }^{1, *(D)}$ and Sima Noghanian ${ }^{2}$ (D) \\ 1 School of Electrical Engineering and Computer Science, University of North Dakota, Grand Forks, \\ ND 58202, USA \\ 2 Phoenix Analysis and Design Technologies Inc., Tempe, AZ 85284, USA; sima_noghanian@ieee.org \\ * Correspondence: mohammad.haerinia@und.edu
}

Received: 25 February 2019; Accepted: 10 April 2019; Published: 11 April 2019

\begin{abstract}
In this work, a dual-band printed planar antenna, operating at two ultra-high frequency bands $(2.5 \mathrm{GHz} / 4.5 \mathrm{GHz})$, is proposed for wireless power transfer for wearable applications. The receiving antenna is printed on a Kapton polyimide-based flexible substrate, and the transmitting antenna is on FR-4 substrate. The receiver antenna occupies $2.1 \mathrm{~cm}^{2}$ area. Antennas were simulated using ANSYS HFSS software and the simulation results are compared with the measurement results.
\end{abstract}

Keywords: dual-band; wearable applications; Kapton

\section{Introduction}

Wearable devices have been of interest due to an increase in their applications, such as the Internet of Things (IoT), biomedical sensors, and body area network. For these particular applications, a reliable and suitable power source is required, especially a method of power transfer that does not rely on batteries or wired power sources. Therefore, wireless power transfer (WPT) has been of interest for recharging wearable devices.

Typically, the WPT systems are divided into two categories, far-field [1] and near-field [2,3] systems. A WPT system requires a transmitting unit connected to the main source of power and the transform the electrical power into an electromagnetic field. One or multiple receivers convert the electromagnetic field to electrical power. WPT technology is also used for energy transfer in wireless sensor networks (WSNs). In these applications, WSN is limited by the battery lifetime [2]. Flexible and textile implementations of WPT have been proposed in literature [4,5]. In [6], the authors designed a wireless power transfer system for a wearable and wireless neurotransmitter sensor recording system. They used a multi-antenna system as a power transmitter to resolve lateral and angular misalignments of the receiver antennas and claimed that it provided better effective coverage. In [7], the authors designed a wearable resonant WPT system for biomedical applications. This system achieved a power transfer efficiency (PTE) of 5.4\% transferring at least $570 \mathrm{~mW}$ of power. Nonetheless, low power transfer efficiency and poor received power stability are the main drawbacks of WPT systems used in biomedical and wearable application [3]. A wearable textile antenna embroidered on fabric for wireless power transfer systems is presented in [8]. The authors used a planar spiral coil generated with the conductive thread on a cotton substrate. This system operates at $6.78 \mathrm{MHz}$, providing $-5.51 \mathrm{~dB}$ transfer efficiency and $12.75 \mathrm{~mW}$ power transmission at a distance of $15 \mathrm{~cm}$. The authors in [9] designed a single band antenna operating at $2.45 \mathrm{GHz}$ intended for wearable and flexible applications. They took advantage of a thermal deposition technique to fabricate antenna structures on a Kapton Polyimide platform. In this case, thin-film deposition was obtained by evaporating a source material in a vacuum allowing vapor particles to travel to the substrate covered with a mask outlining the desired structure. In the work presented in [10], a low-cost inkjet printing method for antenna fabrication on a 
poly-ethylene terephthalate (PET) substrate is utilized. Their proposed co-planar waveguide (CPW) fed Z-shape antenna that was operating at $2.45 \mathrm{GHz}$. The authors measured radiation efficiency of $62 \%$ and the gain of $1.44 \mathrm{dBi}$ at $2.45 \mathrm{GHz}$. An office inkjet printer was used to print silver nanoparticle ink on the PET substrate to fabricate the antenna prototypes. The authors in [11] fabricated a flexible dual-band dipole antenna operating at $900 \mathrm{MHz} / 2.44 \mathrm{GHz}$. They printed their antenna on Kapton through screen-printing technology using a polymer-silver conductor. This antenna is considered in its receiving mode and is connected to a rectifier. This radio frequency (RF) energy harvester was tested in a wireless power transfer scenario. In this dual-band configuration, the system provides $1 \mathrm{~V} D C$ voltage for a power density of $0.7 \frac{\mathrm{mW}}{\mathrm{m}^{2}}$ at $900 \mathrm{MHz}$ and $1.1 \frac{\mathrm{mW}}{\mathrm{m}^{2}}$ at $2.44 \mathrm{GHz}$. The efficiency of WPT systems depends on different factors, such as the geometry of transmitting and receiving elements, misalignment, bending, and the distance between transceivers. Some of these were investigated in [12-18].

There are multiple challenges that should be addressed in using the wireless power transfer method as a source of power for wearable devices. One of the challenges is managing and distributing power between multiple wearable devices [19]. In [19], a WPT technique that distributes power from a single or a few sources between items of clothing is proposed. The authors also studied the power transfer between a pair of trousers and a shirt and provided three models of resonators attached to fabric on the surface of the clothing. In [20], the authors utilized an RF-based wireless power transfer method to transfer power to medical implanted devices, such as cardiac pacemakers. They designed a novel wideband numerical model (WBNM) for implantable antennas to enable RF-powered leadless pacing. The application of this model and the tissue simulating liquid (TSL) was demonstrated by the design, development, manufacture, and measurement of a novel metamaterial-based conformal antenna at $2.4 \mathrm{GHz}$.

Despite the recent progress in implantable electronic devices, there is still a need for a reliable miniature power source. In [21] the authors studied the optimum frequency for power transfer to implanted devices. They concluded that the optimal frequency is above $1 \mathrm{GHz}$ for small receive coil and typical transmit-receive separations. The author in [22] presented a wireless powering method that overcomes the challenge of miniaturization of the power source by inducing spatially focused and adaptive electromagnetic energy transport via propagating modes in tissue. This method has potential application in a new generation of micro-implants microelectromechanical sensors and logic units.

In [23], WPT is used for wearable radio frequency identification (RFID). The authors of [23] illustrated that their proposed wireless transmission structure can operate RFID tags built into smartwatches and claimed that this technology can be adapted to various low-power chips to develop other smart wearable devices, such as smartphones, glasses, and bracelets. In [24], the authors designed a wearable motion sensor on a flexible substrate for mobile health applications. They proposed a compact wireless skin conductance sensor used to monitor the body's emotional regulation process. This flexible substrate can conform to the shape of the user's hand.

The major part of any wireless flexible electronic system is the antenna. The antenna has a direct influence on the efficiency of the systems [4]. The size of the antenna is usually the limiting factor in achieving a reasonable power transfer efficiency. Therefore, antennas that can operate at different bands are desirable, since they can reduce the overall size of the system. In [25] we proposed a dual-band antenna and analyzed the bending effects on its performance. The antenna operates at two ultra-high frequency bands $(1.6 \mathrm{GHz} / 3.6 \mathrm{GHz})$ [25]. The proposed antenna is for wireless power transfer for biomedical applications. This antenna is considered to be printed on a flexible substrate and be implanted inside human body tissue at $10 \mathrm{~mm}$ depth. The performance of the antenna under various bending conditions was studied. It was concluded that the proposed antenna respects safety standards to prevent dangerous effects in humans and the antenna's performance remains stable under bending conditions. Following the work in [25], in this paper, we present a flexible antenna, printed on Kapton, with a total dimension of $15 \mathrm{~mm} \times 14 \mathrm{~mm} \times 0.17 \mathrm{~mm}$, to be integrated with a WPT system. The design, simulation, fabrication, and measurements of the antenna radiation characteristics are 
presented. A comparison of different types of flexible antennas in the literature and the proposed work in this paper is shown in Table 1.

\section{Design and Fabrication}

It is important to choose a substrate material that is tested under bending conditions [26]. Bending, twisting, and rolling tests of the fabricated antenna prototypes presented in [27] show that Kapton is a robust material for designing wearable antenna. Kapton is prone to performance degradation because it resists substrate deformation. In this work, the flexible antenna was designed to be printed on Kapton. We chose Kapton because it has physical robustness, high flexibility, very high durability, high mechanical strength, distortion resistance to harsh environments, thus, enhancing the reliability of the antenna $[4,28]$.

Table 1. Comparison of different types of flexible antennas.

\begin{tabular}{|c|c|c|c|c|c|c|c|}
\hline $\begin{array}{l}\text { Antenna } \\
\text { Parameter }\end{array}$ & $\begin{array}{l}\text { Proposed } \\
\text { Flexible } \\
\text { Dual-Band } \\
\text { Antenna }\end{array}$ & $\begin{array}{c}\text { Poly-Imide } \\
\text { Based Single } \\
\text { Band Antenna } \\
{[27]}\end{array}$ & $\begin{array}{c}\text { Poly-Imide-Based } \\
\text { Dual Band } \\
\text { Antenna [27] }\end{array}$ & $\begin{array}{c}\text { Textile } \\
\text { Antenna } \\
\text { [29] }\end{array}$ & $\begin{array}{c}\text { Paper-Based } \\
\text { Antenna } \\
{[30]}\end{array}$ & $\begin{array}{c}\text { Fluidic } \\
\text { Antenna } \\
\text { [31] }\end{array}$ & $\begin{array}{c}\text { Flexible } \\
\text { Bow-Tie } \\
\text { Antenna } \\
\text { [32] }\end{array}$ \\
\hline Size $\left(\mathrm{mm}^{2}\right)$ & $15 \times 14$ & $26.5 \times 25$ & $35 \times 25$ & $180 \times 150$ & $46 \times 35$ & $54 \times 10$ & $39 \times 25$ \\
\hline Thickness (mm) & 0.17 & 0.05 & 0.05 & 4 & 0.25 & 1 & 0.13 \\
\hline Band & Dual & Single & Dual & Dual & Single & Single & Single \\
\hline $\begin{array}{l}\text { Frequency } \\
(\mathrm{GHz})\end{array}$ & $2.5 / 4.5$ & 2.4 & $2.5 / 5.2$ & $2.2 / 3$ & 2.4 & 1.85 & 7.6 \\
\hline Substrate & Poly-imide & Poly-imide & Poly-imide & Felt fabric & Paper & PDMS & PEN film \\
\hline $\begin{array}{c}\text { Relative } \\
\text { Permittivity }\left(\varepsilon_{r}\right)\end{array}$ & 3.4 & 3.4 & 3.4 & 1.5 & 3.4 & 2.67 & 3.2 \\
\hline Deformability & Low & Low & Low & High & High & High & Low \\
\hline $\begin{array}{l}\text { Thermal } \\
\text { Stability }\end{array}$ & High & High & High & Low & Low & Low & High \\
\hline $\begin{array}{l}\text { Fabrication } \\
\text { Complexity }\end{array}$ & $\begin{array}{l}\text { Simple/ } \\
\text { Printed }\end{array}$ & Simple/Printed & Simple/Printed & $\begin{array}{l}\text { Complex/ } \\
\text { Non-Printed }\end{array}$ & $\begin{array}{l}\text { Simple/ } \\
\text { Printed }\end{array}$ & $\begin{array}{l}\text { Complex/ } \\
\text { Non-Printed }\end{array}$ & $\begin{array}{l}\text { Simple/ } \\
\text { Printed }\end{array}$ \\
\hline
\end{tabular}

The printing material and equipment are described as follows [33]:

PCB Printer, Voltera V-One: Voltera V-One shown in Figure 1 was used to fabricate the antenna. The Gerber file of the antenna design was first imported to V-one software. After calibrating ink and position, the device was set to dispense ink and solder paste onto the substrates.

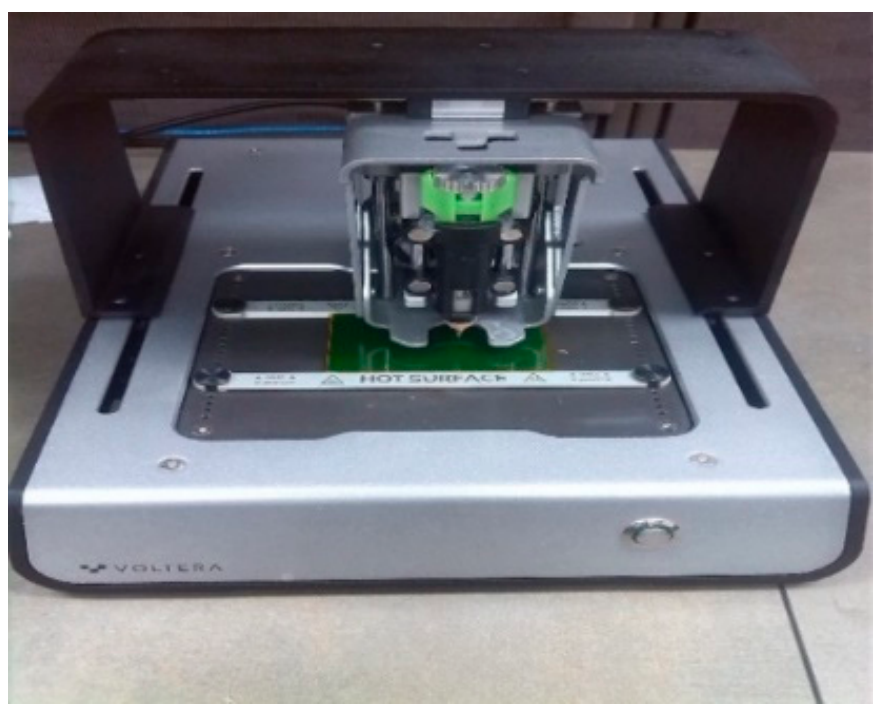

Figure 1. V-one from Voltera was used for fabrication.

Conductive Ink: The conductive ink from Voltera was used for printing transmitting antenna on the FR-4. After thermal curing the ink the antenna is ready for testing. 
Flexible Conductive Ink: For the flexible substrate, the flexible conductive ink (from Voltera) that is compatible with Kapton (polyimide), polycarbonate, PET was used. This specific ink has a curing temperature of $140{ }^{\circ} \mathrm{C}$ for $10 \mathrm{~min}$ or $120^{\circ} \mathrm{C}$ for $30 \mathrm{~min}$.

The proposed microstrip antenna design is based on split-ring elements and can be used at two frequencies $(2.5 \mathrm{GHz} / 4.5 \mathrm{GHz})$. The dimension of the transmitter (TX) and receiver (RX) antennas are $14 \mathrm{~mm} \times 15 \mathrm{~mm}$, occupying a small area.

In this design, a current-probe feeds the outer ring, and the inner ring is considered to provide frequency tuning. The design procedure is presented in [34]. To verify the design, antennas were simulated by ANSYS HFSS (High Frequency Structure Simulator) software [35]. Simulation results were compared with empirical ones. Figure 2 illustrates the proposed antenna. While the overall design of the TX and RX antennas is the same, the substrate materials and thicknesses are different. A rigid substrate (FR-4) with a thickness of $1.56 \mathrm{~mm}$, relative permittivity of 3.66 and dielectric loss tangent of 0.004 was used for the TX. A flexible substrate (Kapton) with a thickness of $0.17 \mathrm{~mm}$, relative permittivity of 3.4 and conductivity of $0.00524 \frac{\mathrm{S}}{\mathrm{m}}$ was used for the RX. Since the substrate materials and thicknesses are different, that resonance frequencies of the TX and RX are not exactly the same. The antennas were simulated in the air and on the muscle tissue. The muscle tissue was assumed to have the relative permittivity of 49.54 , and the conductivity of $4.0448 \frac{\mathrm{S}}{\mathrm{m}}$ obtained from the Institute of Applied Physics (IFAC) database [36].

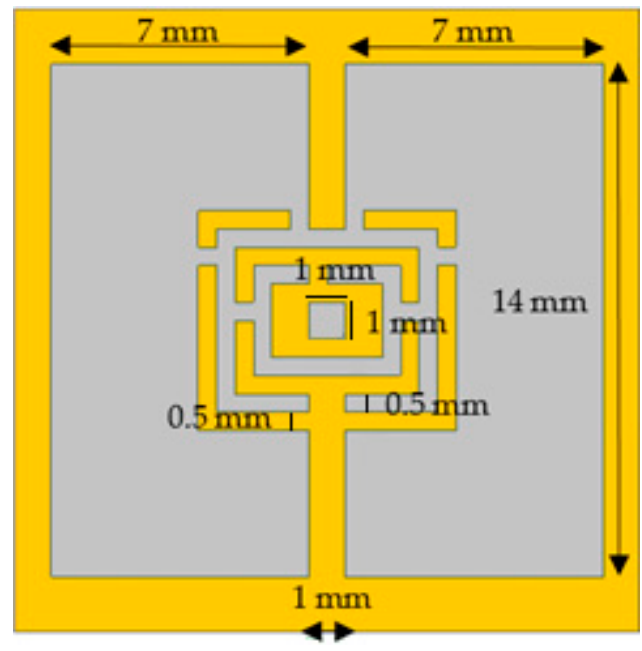

(a)

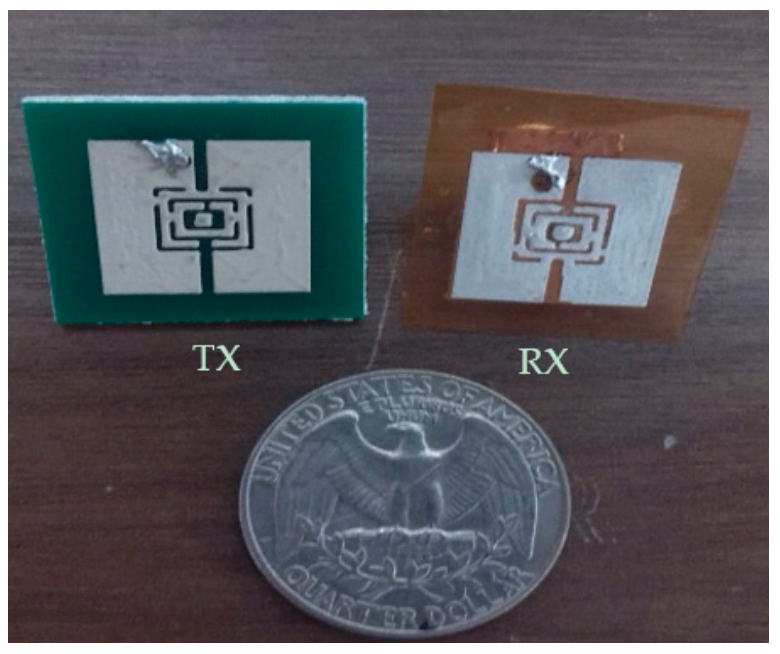

(b)

Figure 2. Transmitter (TX) and receiver (RX) antennas (a) antenna structure parameters, (b) TX and RX fabricated prototypes.

\section{Experimental and Simulation Results}

The location of the receiving antenna while it was placed on a phantom body model is presented in Figure 3a-c. The experimental setup is depicted in Figure 3d. As it is shown in Figure 4a the reflection coefficient for the TX antenna $\left(S_{11}\right)$ is $-19.50 \mathrm{~dB}$ at the first resonance frequency and $-16.90 \mathrm{~dB}$ at the second resonance frequency. The reflection coefficient for the $\mathrm{RX}$ antenna $\left(S_{22}\right)$ is $-15 \mathrm{~dB}$ at the first resonance frequency and $-21.90 \mathrm{~dB}$ at the second resonance frequency. These values are taken from the measurement in free-space. Similarly, Figure $4 \mathrm{~b}$ presents the reflection coefficient for the TX antenna $\left(S_{11}\right)$ is $-17 \mathrm{~dB}$ at the first resonance frequency and $-17.50 \mathrm{~dB}$ at the second one. The reflection coefficient for the RX antenna $\left(S_{22}\right)$ is $-23.60 \mathrm{~dB}$ at the first resonance frequency and $-23.60 \mathrm{~dB}$ at the second one, while it is placed on the muscle tissue. $S_{21}$ in Figure $4 \mathrm{a}, \mathrm{b}$ show the measured and simulated transmission coefficients for free-space and on body phantom cases, respectively. 


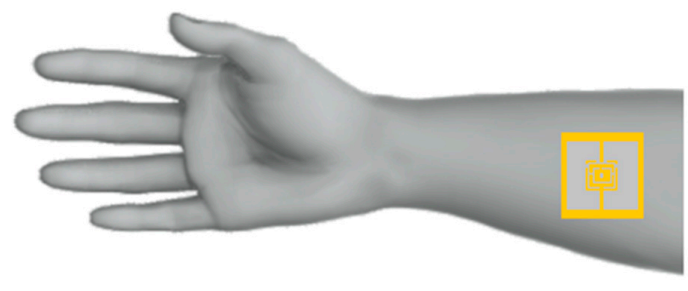

(a)

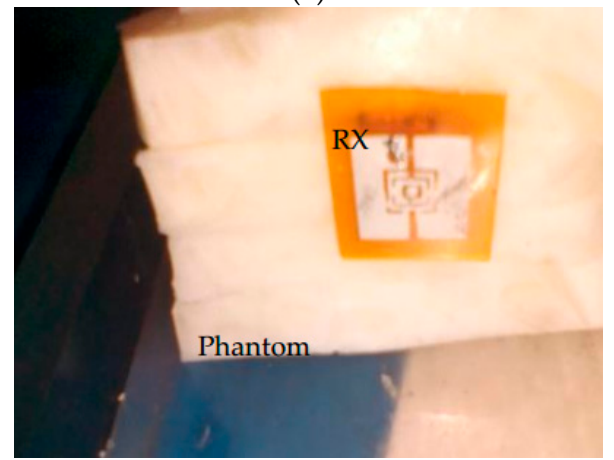

(c)

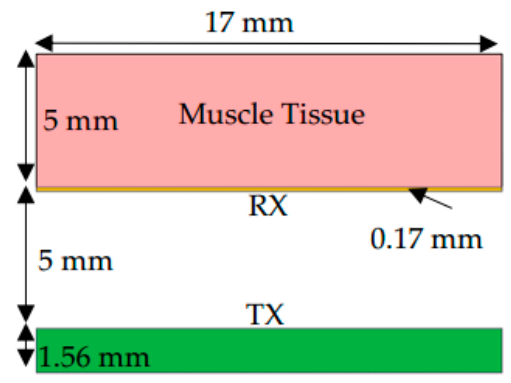

(b)

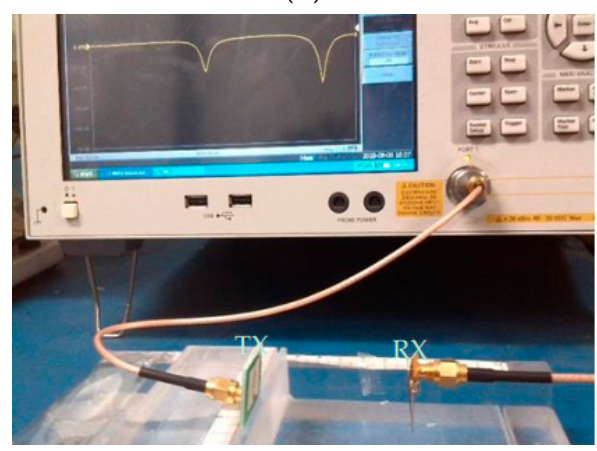

(d)

Figure 3. Proposed antennas (a) wearable antenna on hand, (b) antenna structure, (c) flexible antenna on phantom body model, and (d) experimental setup.

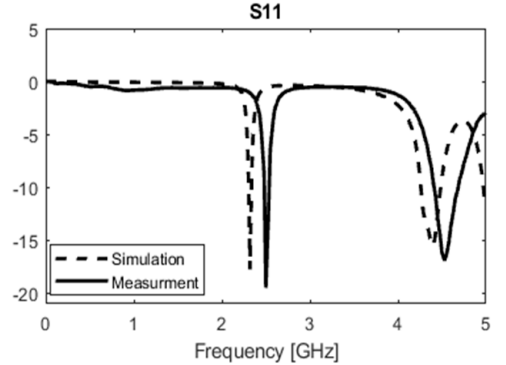

s22

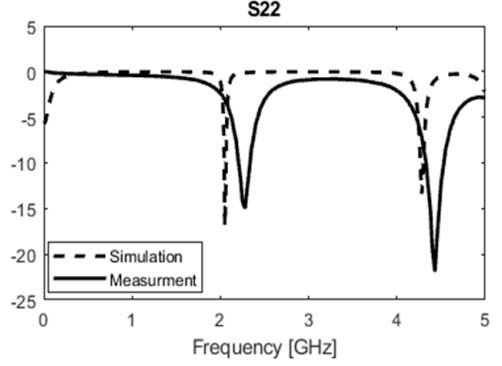

S2

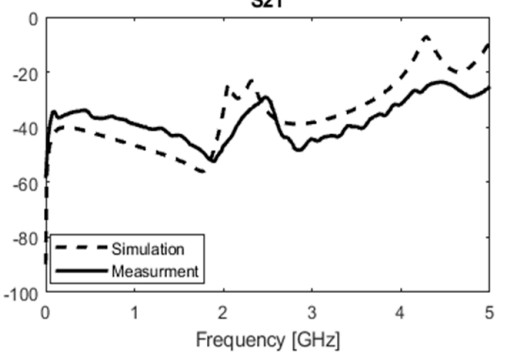

(a)

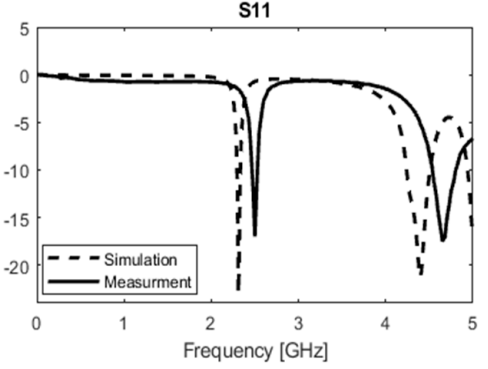

S22

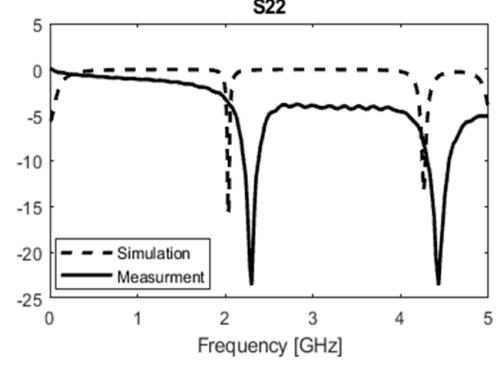

S21

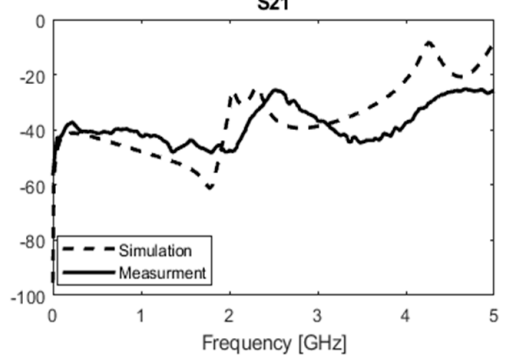

(b)

Figure 4. Scattering parameters $S_{11}, S_{22}$, and $S_{21}$ with $5 \mathrm{~mm}$ gap between the $R X$ and $T X$, the $R X$ is placed on (a) in free space, (b) on phantom. 
It is expected to see a slight difference in resonance frequencies of the TX and RX, due to the differences in the substrate's materials. A slight shift in the measured resonant frequencies compared to simulated ones were due to fabrication discrepancies. Scattering parameters of these antennas at different resonance frequencies are shown in Table 2 . In this paper, $S_{11}$ represents the reflection coefficient for the transmitting antenna (TX), $S_{22}$ provides the reflection coefficient for the receiving antenna (RX), and $S_{21}$ is the transmission coefficient.

Table 2. Resonance frequencies (GHz) (M: Measurement, S: Simulation).

\begin{tabular}{ccccccccc}
\hline & \multicolumn{2}{c}{$\begin{array}{c}\text { Air } \\
\text { (First Resonance) }\end{array}$} & \multicolumn{2}{c}{$\begin{array}{c}\text { Air } \\
\text { (Second Resonance) }\end{array}$} & \multicolumn{2}{c}{$\begin{array}{c}\text { Phantom } \\
\text { (First Resonance) }\end{array}$} & \multicolumn{2}{c}{$\begin{array}{c}\text { Phantom } \\
\text { (Second Resonance) }\end{array}$} \\
\hline Parameter & $\mathbf{M}$ & $\mathbf{S}$ & $\mathbf{M}$ & $\mathbf{S}$ & $\mathbf{M}$ & $\mathbf{S}$ & $\mathbf{M}$ & $\mathbf{S}$ \\
\hline $\mathrm{S}_{11}$ & 2.50 & 2.32 & 4.53 & 4.39 & 2.50 & 2.31 & 4.65 & 4.44 \\
$\mathrm{~S}_{22}$ & 2.28 & 2.05 & 4.43 & 4.28 & 2.30 & 2.03 & 4.43 & 4.26 \\
$\mathrm{~S}_{21}$ & 2.48 & 2.32 & 4.45 & 4.28 & 2.51 & 2.31 & 4.68 & 4.26 \\
\hline
\end{tabular}

The simulated radiation patterns describe how the antenna radiates/receives energy into space. The antenna patterns are generally shown as plots in polar coordinates so the viewers have the ability to easily visualize how the antenna radiates in all directions. The ratio of the power gain in a given direction to the power gain of a reference antenna in the same direction defines the gain of the antenna [37]. The maximum gain of the TX at $2.5 \mathrm{GHz}$ and $4.5 \mathrm{GHz}$ is $-5.34 \mathrm{dBi}$ and $-4.49 \mathrm{dBi}$, respectively, as shown in Figure 5. The radiation pattern was measured while the TX antenna is printed on an FR-4 substrate and was compared to simulation ones, as shown in Figure 6. The measured and simulated antenna specifications are listed in Table 3.

Please note that in this case antennas are not necessarily in the far-field of each other. The antenna efficiency is not relevant in these applications. Instead, transmission efficiency is a good measure of the antenna's performance. We studied the effects of distance on the proposed dual-band antennas' transmission efficiency. To calculate transmission efficiency, we used (1).

$$
\eta=\left|S_{21}\right|^{2} \times 100 \%
$$

where $\eta$ is transmission efficiency and $S_{21}$ is the transmission coefficient. The distance was changed from $5 \mathrm{~mm}$ to $50 \mathrm{~mm}$. The transmission efficiency variation was $3.94 \%$ for the first resonance frequency and $2.29 \%$ for the second one, as shown in Figure 7 . It is concluded that the antenna performance is stable and does not change significantly due to this change of distance.

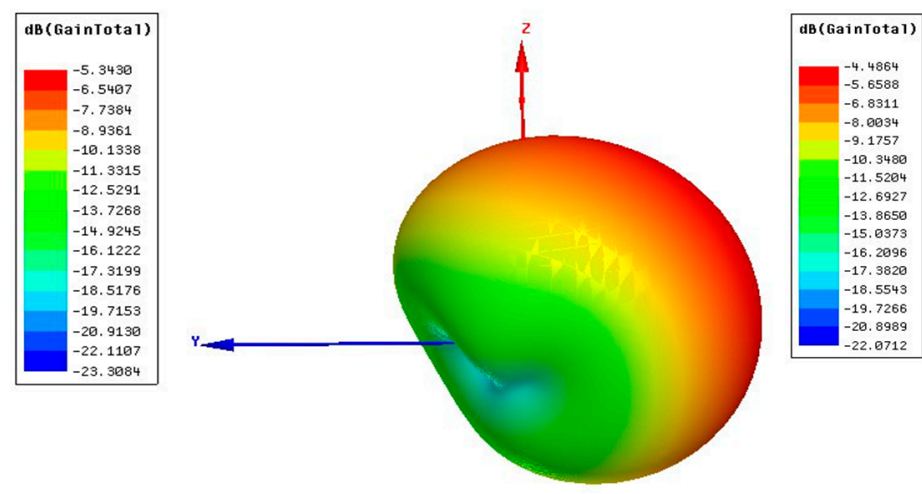

(a)

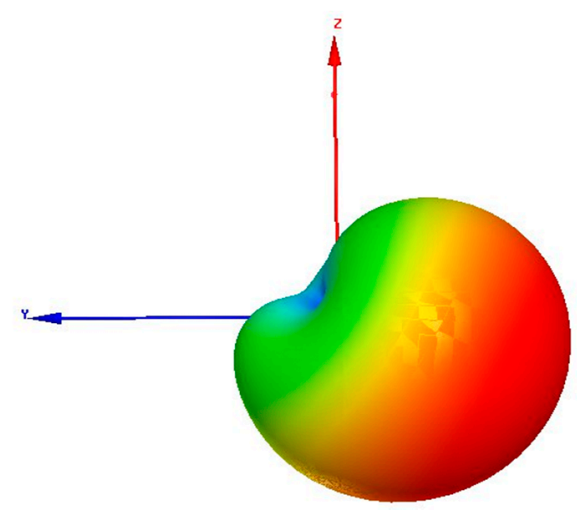

(b)

Figure 5. Total gain of the TX antenna (dBi) (a) at $2.5 \mathrm{GHz},(\mathbf{b})$ at $4.5 \mathrm{GHz}$. 


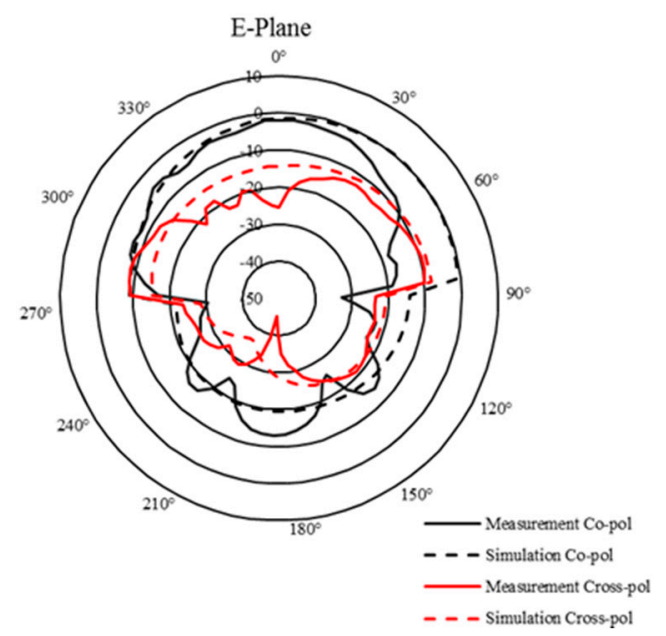

(a)

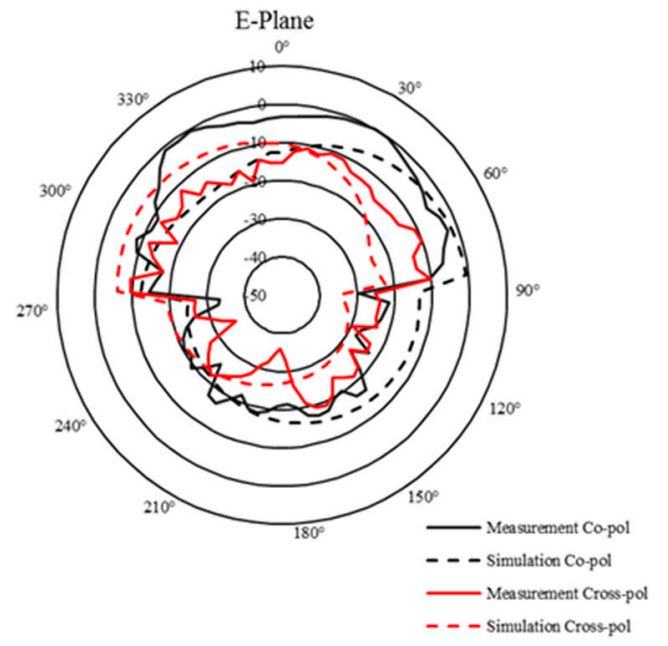

(c)

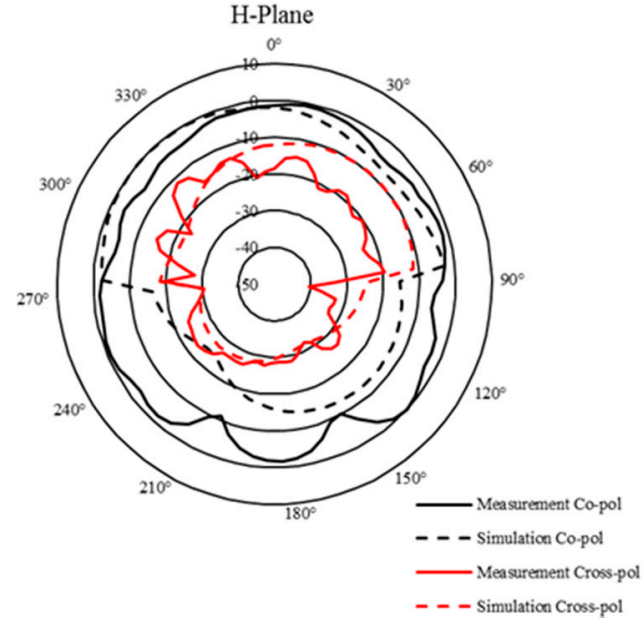

(b)

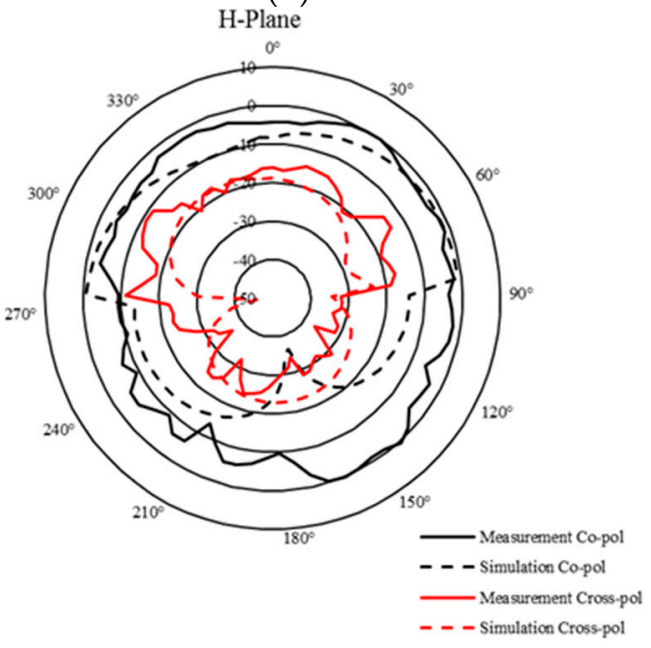

(d)

Figure 6. Radiation patterns of the TX antenna (dB) (a) E-plan at $2.5 \mathrm{GHz},(\mathbf{b}) \mathrm{H}$-plan at $2.5 \mathrm{GHz}$, (c) E-plan at $4.5 \mathrm{GHz}$, (d) H-plan at $4.5 \mathrm{GHz}$.

Table 3. Antenna specifications (M: Measurement, S: Simulation).

\begin{tabular}{ccccccccc}
\hline & \multicolumn{3}{c}{ First Resonance } & \multicolumn{3}{c}{ Second Resonance } \\
\hline \multirow{2}{*}{ Parameter } & E-Plane & E-Plane & H-Plane & H-Plane & E-Plane & E-Plane & H-Plane & H-Plane \\
& $\mathbf{M}$ & $\mathbf{S}$ & $\mathbf{M}$ & $\mathbf{S}$ & $\mathbf{M}$ & $\mathbf{S}$ & $\mathbf{M}$ & $\mathbf{S}$ \\
\hline Directivity $(\mathrm{dBi})$ & 4.57 & 3.98 & 2.94 & 3.59 & 4.45 & 5.21 & 3.61 & 4.19 \\
Gain $(\mathrm{dBi})$ & -6.45 & -5.34 & -6.16 & -5.34 & -5.04 & -4.49 & -4.76 & -4.49 \\
Beam Width $\left(^{\circ}\right)$ & 34 & 35 & 24 & 20 & 48 & 55 & 38 & 30 \\
\hline
\end{tabular}

The maximum permissible exposure (MPE) in uncontrolled environments for electromagnetic field strengths is evaluated by the value of specific absorption rate (SAR). Based on IEEE Std. C95.1, SAR should be below $0.08 \frac{\mathrm{W}}{\mathrm{kg}}$ as averaged over the whole body and the maximum SAR value should be below $1.6 \frac{\mathrm{W}}{\mathrm{kg}}$ as averaged over any $1 \mathrm{~g}$ of the tissue. However, the maximum SAR value should be below $4 \frac{\mathrm{W}}{\mathrm{kg}}$ as averaged over any $10 \mathrm{~g}$ of the tissue for the hands, feet, ankles, and wrists [38]. As it is indicated in Figure 8, the maximum absorption rate is $0.21 \frac{\mathrm{W}}{\mathrm{kg}}$ at $2.5 \mathrm{GHz}$ and $0.57 \frac{\mathrm{W}}{\mathrm{kg}}$ at $4.5 \mathrm{GHz}$. The proposed antenna is within the safety standards. 


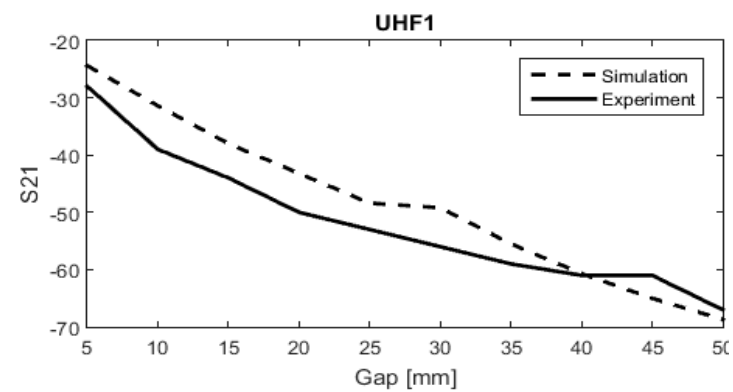

(a)

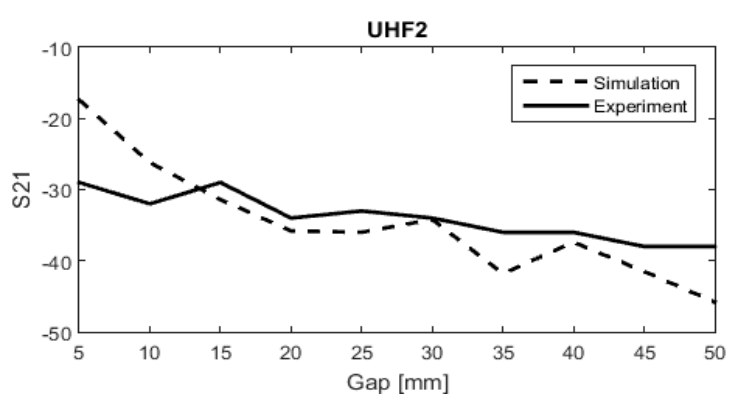

(b)

Figure 7. Simulated and measured transmission coefficient $\left(S_{21}\right)$ versus distance between the transmitter (TX) and receiver (RX) antennas (a) at $2.5 \mathrm{GHz},(\mathbf{b})$ at $4.5 \mathrm{GHz}$.

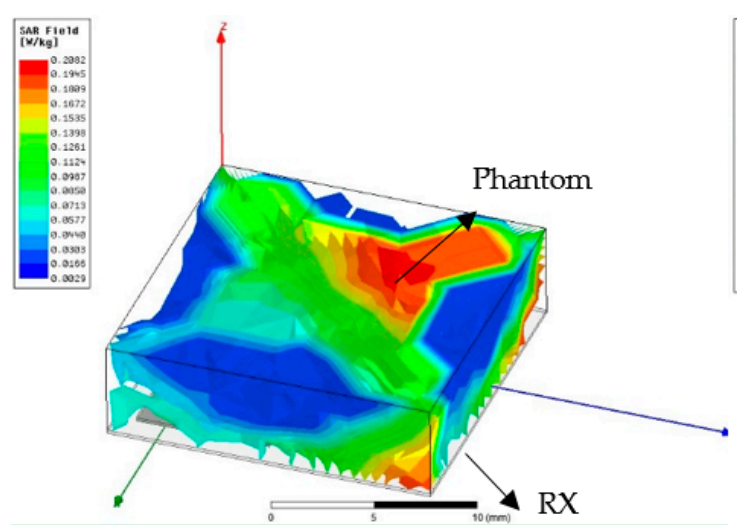

(a)
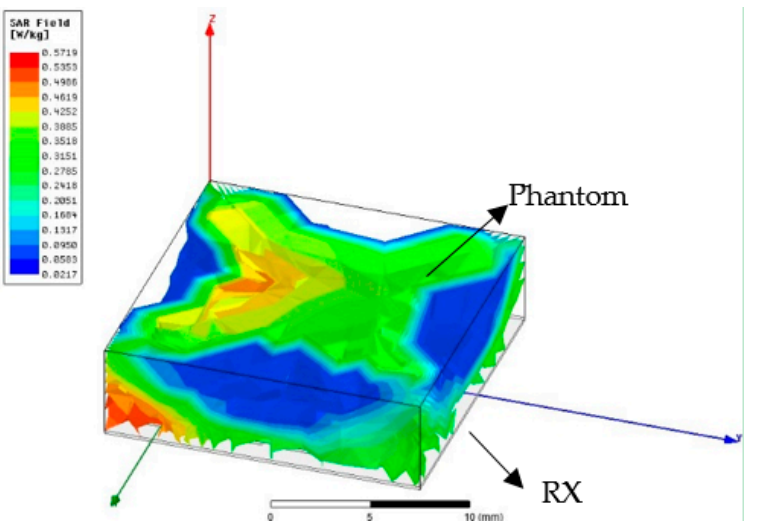

(b)

Figure 8. SAR distributions in Phantom (W/ kg) (a) at $2.5 \mathrm{GHz}$, and (b) at $4.5 \mathrm{GHz}$.

\section{Conclusions}

It is important to study flexible small antennas for the use of microwave power transfer (MPT) in wearable applications. In this work, we proposed a dual-band antenna operating at ultra-high frequency antenna $(2.5 \mathrm{GHz} / 4.5 \mathrm{GHz})$ for MPT applications. The antennas were based on split ring resonator. The shape of the antenna provides multiple dimensions that can be optimized for the desired frequency. We proposed a small antenna with the area of $14 \mathrm{~mm} \times 15 \mathrm{~mm}$. The proposed design can be modified for other frequency bands. The proposed antenna provides near omni-directional radiation pattern that is desirable for wearable WPT. The transmission efficiency does not vary significantly due to change of distance. The SAR values were also examined. In future, the effect of bending and crumpling on the power efficiency will be investigated. The design will be optimized for various bending conditions.

Author Contributions: Conceptualization, M.H. and S.N.; methodology, M.H. and S.N.; software simulation, M.H.; validation, M.H., and S.N.; formal analysis, M.H.; investigation, M.H., and S.N.; resources, S.N.; writing-original draft preparation, M.H.; writing-review and editing, S.N.; supervision, S.N.; project administration, S.N.; funding acquisition, S.N.

Funding: North Dakota Department of Commerce, Venture Phase I, DoC \#16-02-J1-112.

Acknowledgments: The financial support from North Dakota Department of Commerce through a Venture Phase I grant is appreciated. The financial support of the School of Electrical Engineering and Computer Science is acknowledged.

Conflicts of Interest: The authors declare no conflict of interest. 


\section{References}

1. Garnica, J.; Chinga, R.A.; Lin, J. Wireless Power Transmission: From Far Field to Near Field. Proc. IEEE 2013, 101, 1321-1331. [CrossRef]

2. Jawad, A.M.; Nordin, R.; Gharghan, S.K.; Jawad, H.M.; Ismail, M. Opportunities and Challenges for Near-Field Wireless Power Transfer: A Review. Energies 2017, 10, 1022.

3. Shadid, R.; Noghanian, S. A Literature Survey on Wireless Power Transfer for Biomedical Devices. Int. J. Antennas Propag. 2018. [CrossRef]

4. Khaleel, R.H.; Al-Rizzo, M.H.; Abbosh, I.A. Design, Fabrication, and Testing of Flexible Antennas. Adv. Microstrip Antennas Recent Appl. 2013, 363-383.

5. Zhu, D.; Grabham, N.J.; Clare, L.; Stark, B.H.; Beeby, S.P. Inductive power transfer in e-textile applications: Reducing the effects of coil misalignment. In Proceedings of the 2015 IEEE Wireless Power Transfer Conference, WPTC 2015, Boulder, CO, USA, 13-15 May 2015; pp. 1-4. [CrossRef]

6. Nguyen, C.M.; Kota, P.K.; Nguyen, M.Q.; Dubey, S.; Rao, S.; Mays, J.; Chiao, J.C. Wireless power transfer for autonomous wearable neurotransmitter sensors. Sensors 2015, 15, 24553-24572.

7. Basar, M.R.; Ahmad, M.Y.; Cho, J.; Ibrahim, F.B. An Improved Wearable Resonant Wireless Power Transfer System for Biomedical Capsule Endoscope. IEEE Trans. Ind. Electron. 2018, 65, 7772-7781. [CrossRef]

8. Heo, E.; Choi, K.Y.; Kim, J.; Park, J.H.; Lee, H. A wearable textile antenna for wireless power transfer by magnetic resonance. Text. Res. J. 2018, 88, 913-921. [CrossRef]

9. Letcher, J.; Tierney, D.; Raad, H. Fabrication of Wearable Antennas through Thermal Deposition. Int. Sch. Sci. Res. Innov. 2017, 11, 183-186.

10. Paracha, K.N.; Rahim, S.K.A.; Chattha, H.T.; Aljaafreh, S.S.; Ur Rehman, S.; Lo, Y.C. Low-cost printed flexible antenna by using an office printer for conformal applications. Int. J. Antennas Propag. 2018, 2018, 1-7. [CrossRef]

11. Berges, R.; Fadel, L.; Oyhenart, L.; Vigneras, V.; Berges, R.; Fadel, L.; Oyhenart, L.; Vigneras, V.; Flexible, T.T.A.; Berges, R.; et al. A Flexible printed dual-band antenna dedicated to RF Energy Harvesting Application. Journées Nationalessur la Récupération et le Stockage d'Énergie 2017, Hal-01484377.

12. Haerinia, M.; Mosallanejad, A.; Afjei, E.S. Electromagnetic analysis of different geometry of transmitting coils for wireless power transmission applications. Prog. Electromagn. Res. M 2016, 50, 161-168. [CrossRef]

13. Haerinia, M.; Afjei, E.S. Resonant inductive coupling as a potential means for wireless power transfer to printed spiral coil. J. Electr. Eng. 2016, 16, 65-74.

14. Haerinia, M.; Afjei, E.S. Design and analysis of class EF2 inverter for driving transmitting printed spiral coil. J. Electr. Eng. 2018, 18, 1-5.

15. Haerinia, M. Modeling and simulation of inductive-based wireless power transmission systems. In Book Energy Harvesting for Wireless Sensor Networks: Technology, Components and System Design, 1st ed.; Olfa, K., Ed.; De Gruyter: Berlin, Germany; Boston, MA, USA, 2018; pp. 197-220. [CrossRef]

16. Haerinia, M.; Noghanian, S. Analysis of misalignment effects on link budget of an implantable antenna. In Proceedings of the URSI EM Theory Symposium, EMTS 2019, San Diego, CA, USA, 27-31 May 2019, accepted.

17. Haerinia, M.; Noghanian, S. Design of hybrid wireless power transfer and dual ultrahigh-frequency antenna system. In Proceedings of the URSI EM Theory Symposium, EMTS 2019, San Diego, CA, USA, 27-31 May 2019, accepted.

18. Shadid, R.; Haerinia, M.; Sayan, R.; Noghanian, S. Hybrid Inductive Power Transfer and Wireless Antenna System for Biomedical Implanted Devices. Prog. Electromagn. Res. C 2018, 88, 77-88.

19. Miyamura, K.; Miyaji, Y.; Ohmura, R. Feasibility study on wireless power transfer for wearable devices. In Proceedings of the 2017 ACM International Symposium on Wearable Computers, Maui, HI, USA, 11-15 September 2017; pp. 166-167.

20. Asif, S.M.; Iftikhar, A.; Braaten, B.D.; Ewert, D.L.; Maile, K. A Wide-Band Tissue Numerical Model for Deeply Implantable Antennas for RF-Powered Leadless Pacemakers. IEEE Access 2019, 7, 1.

21. Poon, A.S.Y.; O’Driscoll, S.; Meng, T.H. Optimal Frequency for Wireless Power Transmission Into Dispersive Tissue. IEEE T. Antenn. Propag. 2010, 58, 1739-1750. [CrossRef]

22. Patlolla, B.; Yeh, A.J.; Beygui, R.E.; Poon, A.S.Y.; Tanabe, Y.; Neofytou, E.; Kim, S.; Ho, J.S. Wireless power transfer to deep-tissue microimplants. Proc. Natl. Acad. Sci. USA 2014, 111, 7974-7979. 
23. Lin, D.B.; Wang, T.H.; Chen, F.J. Wireless power transfer via RFID technology for wearable device applications. In Proceedings of the 2015 IEEE MTT-S 2015 International Microwave Workshop Series on RF and Wireless Technologies for Biomedical and Healthcare Applications (IMWS-BIO), Taipei, Taiwan, 21-23 September 2015; pp. 210-211.

24. Lam, L.K.; Szypula, A.J. Wearable emotion sensor on flexible substrate for mobile health applications. In Proceedings of the 2018 IEEE Sensors Applications Symposium (SAS), Seoul, Korea, 12-14 March 2018; pp. 1-5.

25. Haerinia, M.; Noghanian, S. Study of Bending Effects on a Dual-Band Implantable Antenna. In Proceedings of the USNC/URSI National Radio Science Meeting, Atlanta, GA, USA, 7-12 July 2019, accepted.

26. Ahmed, S.; Tahir, F.A.; Shamim, A.; Cheema, H.M. A Compact Kapton-Based Inkjet-Printed Multiband Antenna for Flexible Wireless Devices. IEEE Antennas Wirel. Propag. Lett. 2015, 14, 1802-1805.

27. Khaleel, H.R.; Al-Rizzo, H.M.; Rucker, D.G. Compact polyimide-based antennas for flexible displays. IEEE/OSA J. Disp. Technol. 2012, 8, 91-96.

28. Misran, M.H.; Rahim, S.K.A.; Eteng, A.A.; Vandenbosch, G.A.E. Assessment of Kapton-based flexible antenna for near field wireless energy transfer. Appl. Comput. Electromagn. Soc. J. 2017, 32, 31-36.

29. Salonen, P.; Jaehoon, K.; Rahmat-Samii, Y. Dual-band E-shaped patch wearable textile antenna. In Proceedings of the IEEE Antennas and Propagation Society, AP-S International Symposium (Digest), Washington, DC, USA, 3-8 July 2005; pp. 466-469.

30. Anagnostou, D.E.; Gheethan, A.A.; Amert, A.K.; Whites, K.W. A direct-write printed antenna on paper-based organic substrate for flexible displays and WLAN applications. IEEE/OSA J. Disp. Technol. 2010, 6, 558-564. [CrossRef]

31. So, J.H.; Thelen, J.; Qusba, A.; Hayes, G.J.; Lazzi, G.; Dickey, M.D. Reversibly deformable and mechanically tunable fluidic antennas. Adv. Funct. Mater. 2009, 19, 3632-3637.

32. Durgun, A.C.; Reese, M.S.; Balanis, C.A.; Birtcher, C.R.; Allee, D.R.; Venugopal, S. Flexible bow-tie antennas. In Proceedings of the 2010 IEEE International Symposium on Antennas and Propagation and CNC-USNC/URSI Radio Science Meeting-Leading the Wave, AP-S/URSI 2010, Toronto, ON, Canada, 11-17 July 2010; pp. 1-4.

33. Voltera. Available online: http:/ / www.voltera.io (accessed on 28 August 2018).

34. Basaran, S.C.; E Erdeml, Y. Dual-Band Split-Ring Antenna Design for WLAN Free-space Finite Elements. Turk. J. Electr. Eng. 2008, 16, 79-86.

35. ANSYS, Inc. Available online: https://www.ansys.com/products/electronics/ansys-hfss (accessed on 10 April 2019).

36. Institute of Applied Physics (IFAC). Available online: http://niremf.ifac.cnr.it/tissprop/htmlclie/htmlclie. php (accessed on 10 December 2018).

37. Antenna Patterns and Their Meaning. Available online: https:/ /www.cisco.com (accessed on 15 December 2018).

38. Institute of Electrical and Electronics Engineers (IEEE). IEEE Standard for Safety Levels with Respect to Human Exposure to Radio Frequency Electromagnetic Fields, $3 \mathrm{kHz}$ to $300 \mathrm{GHz}$; IEEE: Piscataway, NJ, USA, 1999; ISBN 155937179X.

(C) 2019 by the authors. Licensee MDPI, Basel, Switzerland. This article is an open access article distributed under the terms and conditions of the Creative Commons Attribution (CC BY) license (http:/ / creativecommons.org/licenses/by/4.0/). 